3 Research Square

\title{
A Qualitative Exploration of COVID-19 through Self- reported Experiences via Digital Media
}

\section{Michael Opeoluwa Ogunlana ( $\square$ ogunlanam@ukzn.ac.za )}

College of Health Sciences, University of KwaZulu-Natal https://orcid.org/0000-0001-6877-6938

\section{Pragashnie Govender}

School of Health Sciences University of KwaZulu-Natal https://orcid.org/0000-0003-3155-3743

\section{Research Article}

Keywords: COVID-19, SARS-CoV-2, coronavirus, pandemic, lived experiences, digital media

Posted Date: June 22nd, 2020

DOI: https://doi.org/10.21203/rs.3.rs-36563/v1

License: (9) (1) This work is licensed under a Creative Commons Attribution 4.0 International License. Read Full License 


\section{Abstract}

Background: Research imperatives around COVID-19 require an embrace of its complexity by the inclusion of multi-dimensional perspectives such as lived experiences of persons diagnosed with the disease. This study documents the symptom trends and timelines of COVID-19 as self-reported by individuals in addition to the psychosocial sequelae associated with a positive COVID-19 diagnosis.

Methods: This study followed an explorative qualitative design and included curated online dairies and interviews of individuals diagnosed with COVID-19. Judgemental convenient sampling was used to access 28 self-reports via digital media between 05 March and 05 April 2020. Demographic details were extracted where possible and included a diversity of cases. Data were analysed thematically using inductive reasoning.

Results: Reports revealed a plethora of symptoms associated with the pulmonary system like shortness of breath and cough while another group of symptoms shows extra-pulmonary affectations. The lived experience of these individuals as analysed from their self-reports generated five emergent themes followed after analysis which included (i) the variability of the severity and presentation of the disease, (ii) the $3 \mathrm{~F}$ (fright, fight or flight) response, (iii) moral obligation and personal agency, (iv) voicing vulnerabilities and harnessing hope, (v) silencing stigma.

Conclusions: COVID-19 presents with biopsychosocial affectation on the person. A multidimensional approach is required from all concerned to mitigate its effects.

\section{Background}

Outbreaks of coronavirus infections are not new to the world. The SARS-CoV-2 is the third serious Coronavirus outbreak in less than 20 years, following Severe Acute Respiratory Syndrome (SARS) in 2002-2003 and Middle Eastern Respiratory Syndrome (MERS) in 2012. Researchers have compiled signs and symptoms of the COVID-19. Huang et al (1) reported that patients $(n=41)$ suffered from fever, malaise, dry cough, and dyspnea. Chest computerized tomography (CT) scans showed pneumonia with abnormal findings in all cases. About a third of those $(13,32 \%)$ required Intensive Care Unit (ICU) admission, and there were six (15\%) fatal cases. In another publication by Chen et al (2) it was reported that this disease is estimated to have a mean incubation period of 5.2 days and commonly causes fever, cough, myalgia, and pneumonia in patients. Digestive symptoms such as diarrhoea, may be a presenting feature of COVID-19 (3). Presently it appears that the descriptions of the COVID-19 symptoms are nebulous as without a positive real-time Reverse Transcription Polymerase Chain Reaction (RT-PCR) results there is no unique symptom that can be used for screening patients with COVID-19. An exploration into the trend and timeline of the symptoms reported by patients (4) with a positive SARS-CoV-2 diagnosis may be useful in accurately delineating COVID-19 specific symptoms as reported by patients affected by this disease. 
Apart from routine biomedical derangement, psychological impairment has been reported to be associated indirectly with COVID-19. While Tan et al (5) reported that nonmedical health care personnel are at highest risk for psychological distress during the COVID-19 outbreak; Li et al (6) concluded that vicarious traumatization scores for front-line nurses including scores for physiological and psychological responses, were significantly lower than those of non-front-line nurses. Interestingly, the vicarious traumatization scores of the general public were significantly higher than those of the front-line nurses. Qiu et al (7) reported 35\% of the Chinese populace surveyed expressed a form of psychological distress. It appears no study as explored the overall experiences of patients having a positive SARS-CoV-2 diagnosis. The knowledge of COVID-19 symptom's trend and timeline with its associated psychosocial sequelae may serve the merit of demystifying a disease that has been described by the president of the People's Republic of China as a "demon" while ruminating on its virulence and mortality rates (8). The COVID-19 discourse has taken on variable forms and shapes and scientific communities are therefore racing to provide the evidence that can assist in mitigating the resultant effects. Consequently, research imperatives around COVID-19 require an embrace of its complexity by the inclusion of multi-dimensional perspectives. Part of this response is a call for inclusion of people with lived experience $(9,10)$.

In this study, the authors document the symptom trends and timelines of COVID-19 as self-reported by individuals in addition to the psychosocial sequelae associated with a positive COVID-19 diagnosis.

\section{Methods}

The relevant domains of the consolidated criteria for reporting qualitative research (COREQ) (11) are used to report the methods in this study.

\section{Research Team and Reflexivity}

At the time of this study, the authors, MOO (clinician and clinical researcher from Nigeria) and PG (academic and researcher from South Africa) were in South Africa who had just reported their first cases of COVID-19 on the 5 March 2020. Interest in the area was therefore collectively ignited, the study was conceptualized and ethical considerations negotiated, being cognisant of the developing situation.

\section{Study Design}

Methodological orientation: This study followed an explorative qualitative design within an interpretivist paradigm.

Study Setting: Curated online dairies and interviews of individuals diagnosed with COVID-19 were retrieved from digital media over a one month period.

Participant Selection: Judgemental convenient sampling (12) was used to access 28 self-reports between 05 March and 05 April 2020. Demographic detail was extracted where possible, and included a diversity of included cases. We analysed reports from $n=19$ female and $n=9$ males all of whom reported a laboratory-confirmed COVID-19 diagnosis. Reports included those from USA $(n=11)$; South Africa $(n=7)$; 
United Kingdom ( $n=3)$; Canada $(n=1)$; Nigeria $(n=1)$ Italy $(n=1)$; Australia $(n=1)$; Malaysia $(n=1)$; Unknown $(n=2)$. Digital media included digital news/magazine interviews $(n=11)$; twitter $(n=5)$; Instagram $(n=9)$ and Facebook $(n=3)$. Suspected transmission included travel history to either parts of Europe, the Middle East and/or Asia ( $n=10)$, suspicion of community transmission in 12 cases, (which included attendance at public gatherings such as a concert, festival and religious gathering). Age was specified in only 12 of the cases; this ranged between 22-73 years (median age 28.5years). Comorbidities were reported in five cases and included cancer, lupus with pregnancy, endometriosis with adenomyositis, diabetes and asthma.

\section{Data Analysis}

Initial data analysis involved the extraction of relevant symptoms according to the reported timelines (per day) against each case by MOO and PG. Symptoms were coded as reported and aggregated into counts as they reoccurred among the cases. The proportion of the symptom occurrence was then estimated by dividing the symptom counts by the total number of cases reporting symptoms. These proportions were further presented in percentages to represent the prevalence of symptoms in that timeline. We acknowledged the possibility of recall bias as well as the subjectivity of the accounts in this process. We therefore settled on presenting the resultant symptoms (pooled for all participants) according to general initial symptoms, symptoms within the first five days and symptoms from six days onwards. We subsequently re-read the transcripts for the individual experiences, and initiated a second round of integrated analysis, that involved both authors developing initial codes and categories which were then merged to form themes (13). Inductive reasoning was employed and NVIVO version 11 software was used to manage the data. Verbatim quotes as thick descriptions are used to accentuate the assertions made by the authors. In this process of analysis, we were able to extract information that contributed to the overall account of COVID-19 symptom trend and timelines as well as the lived experiences, while retaining connection to the individual cases. Rigour, credibility, and transparency of the process was maintained using two coders and investigator triangulation, a systematic coding process, peer debriefing, and audit trail (12).

\section{Results}

Symptom prevalence and an exposition of the lived experiences of participants are presented. Pseudonyms are used to de-identify cases where the spoken word is quoted.

\section{Symptom Prevalence}

General initial symptoms (Figure 1), symptom prevalence within the first five days of initial presentation (Figure 2) and symptom prevalence at 6 days to 22 days (Figure 3 ) are reported. A cursory look at the general initial symptoms (Figure 1) reveals that the main symptom that majority of the patients reported was shortness of breath (42.9\%) followed by cough $(35.7 \%)$ and headaches (35.7\%). But as the condition unfolded with increasing number of days, shortness of breath (67\%) and easy fatigability (67\%) were most prevalent amongst the reported cases in the first 5 days of symptom onset (Figure 2). Fever (57\%) 
and cough (57\%) were evenly prevalent at this stage and by six days and beyond (Figure 3 ) chills and shivering $(67 \%)$ became more prevalent than shortness of breath (44\%) and easy fatigability $(67 \%)$ remained persistent.

\section{Lived Experiences of COVID-19}

Five emergent themes followed the analysis of the self-reports, and included (i) the variability of the severity and presentation of the disease, (ii) the $3 \mathrm{~F}$ (fright, fight or flight) response, (iii) moral obligation and personal agency, (iv) voicing vulnerabilities and harnessing hope, (v) silencing stigma. These are augmented by verbatim quotes.

\section{Variability of the Severity and Presentation of the Disease}

The disease appeared to manifest differently amongst the cases. The experiences occurred over a continuum, whilst some individuals remained asymptomatic; others experienced mild symptoms and others a more severe course of the disease.

"I never had symptoms, I was just dealing with something that I don't know" (Constance*, age unspecified, South Africa, Digital news)

"I have dealt with colds in the past that were worse than this" (Wanda*, 22 years, USA, Twitter)

"...myself young, relatively fit, it was mild. There was fever, there was coughing and I think I got off pretty easy" (Tony*, Age unspecified, Canada, Digital News)

"I think we have to calm down because for most people like myself, it's just a long cold that we can shake off..." (Belinda*, 29 years, Australia, Digital News)

"I had bad flu and it's gotten quite worse than this. That's the most frustrating thing about this, is that you don't know. It comes and goes. I wake up in the morning and I'm not feeling great, then I feel okay, then I feel worse again." (Anton*, 40 years, South Africa, Digital News Interview)

"It wasn't touch and go, it was all go. It was bad..."I'm in pretty good shape so the virus was like, I'm gona fix you, you think you're healthy, let me show you what I do to healthy people, and it started turning my lungs into glass" (Kirk*, 55 years, USA, Facebook)

"I had never been this ill in my entire life, I was genuinely afraid I would die because that is what it felt like" (Alice*, 22 years, USA, Twitter)

\section{F Response (Fright, Fight or Flight)}

It would appear that there are a number of ways individuals responded to the disease as a threat. There were those who were fearful and experienced somewhat of an existential crises (fright); those that 
demonstrated strength, resilience and positivity (fight) and those that attempted to 'travel' to a place of safety as part of their coping (flight).

"...you choke, you throw up, the pain, the headache... but that's what keeps you alive. ... you think you're gona die during those episodes, you know you're gona die, but then you don't... when your doctor says to you there's nothing we can do, and you need to pray and beg God for mercy" (Kirk*, 55 years, USA, Facebook)

"I woke from sleep and was crying. I got to the isolation centre, but no one was there to receive me. I waited in the ambulance for two hours. The nurses eventually came out and treated me like a plague. I sat in the ambulance feeling rejected... "I thought I was going to die and contemplate(d) a succession plan" (Abiona*, age unspecified, Nigeria, Twitter)

"I was isolated; I found great strength in the doctors and paramedics, a lesson in humanity and professionalism, and of impressive dedication."(Alberto*, 63 years, Italy, Facebook)

"I just followed the instructions even though I couldn't accept the fact that l'd been infected. I couldn't believe what I was hearing I thought maybe the test results were wrong. I thought to myself, this is the end of my life-but I have not done many things yet"(Adam*, 32 years, Malaysia, Facebook)

"This isn't just the flu - and you aren't invincible... asked my mom if I was dying today" (Lara*, age unspecified, USA, Instagram)

"Fear constantly lurking in the corner-waiting for a weak moment to pounce and invade, stealing all hope, while aggressively scattering thoughts of doom and destruction across the perimeter of your heart...and the temptation remains to tell ourselves we are safe at home" (Elizabeth*, age unspecified, USA, Instagram)

"Firstly, I had to talk to myself and meditate and say to me that this is happening and you need to accept it-it takes self-acceptance to be able to deal with the situation" (Constance*, age unspecified, South Africa, Digital news)

"and it came down to those moments of truth, where they can either lie to you or tell you the truth, no one could tell me I was gonna live" (Kirk*, 55 years, USA, Facebook)

\section{Moral Obligation and Personal Agency}

Innate within these stories, was the acute awareness of humanity. The nihilism of the experiences for some were transcended by intentions and acts towards non-maleficence. Individuals claimed to have acted decisively by self-isolation and seeking medical assistance. Personal agency was enacted by thoughts and actions towards valuing and protecting the rights of others, as manifested in their responses to the disease. 
"I made a ham sandwich on the floor of my kitchen because I could not get up against the counter and table... I ate my sandwich on the floor with my employees at the door, begging me to let them in the house - I said no." (Kirk*, 55 years, USA, Facebook)

"I am petrified for my parents, I'm petrified of the impact that I can have on my parents and the elderly and weak people in society and that's what everyone needs to take home" (Anton*, 40 years, South Africa, Digital News Interview)

"...I work at the intersection of social justice and wellness, so I took this very seriously as an ally, I thought that would be my role, protecting the elderly, the auto immune suppressed" (Felicity*, 26 years, USA, Digital News)

"I wanna be a voice for this crazy virus but also show that I am ok... yeah everyone just try to stay calm and don't get engulfed by all of the fear - I am a COVID-19 patient and I am doing really good." (Kate*, age unspecified, USA, Instagram)

"... what you need to be scared about is the impact that you're gonna have on society when you got it. That is what we need to be scared of... we put ourselves in the centre of the universe, everything is about us, and this virus comes along and if we are gona have this attitude that it is all about us then its gona win...if we start caring about the community and our impact in the community, then we are going to win" (Anton*, 40 years, South Africa, Digital News Interview)

"I had to stay indoors... I had to do it-for my children's sake, for the community's sake for everybody's sake..this is real, let's not take it for granted if you don't quarantine and lockdown as you supposed to be doing we are not going to beat this pandemic" (Constance*, age unspecified, South Africa, Digital news)

"a coronavirus diagnosis is dehumanising and lonely, and I wouldn't wish it on my worst enemy. You aren't invincible because you are in your 20's. take it from me and quarantine like your life depends on it (it might)" (Alice*, 22 years, USA, Twitter)

"The bigger issue is considering the sick and elderly in our community and keeping them away from people like me" (Kayla*, age unspecified, South Africa, Digital News)

\section{Voicing Vulnerabilities and Harnessing Hope}

The universality of being human, with vulnerabilities comes through strongly in some of the expressions, this together with interspersions of hope and even catharsis, by use of digital media in connecting with others. Spirituality also appeared to reside at the heart of acceptance in some cases, affording assurance of an ultimate horizon of well-being.

"...entrust yourself with confidence to those who are taking care of you, feeling at every moment that recovery is possible. This does not always happen, but it is necessary to keep hope alive" (Alberto*, 63 years, Italy, Facebook) 
"I'm miserable and need a safe space to share. To connect. To not be lonely." (Chanel*, Instagram, unspecified age and country)

"It's really been incredible to watch everyone bond together in a mindful and conscious way, use technology as a conscious tool rather than just an app or a medium that we can share flippantly...this has been super cathartic for me.." (Lara*, age unspecified, USA, Instagram)

"We are confident that everything will turn out okay...I hear how people are going crazy about the virus but nobody fears eternity without God in the same way... I am not afraid of death" (Elsabe*, 43 years, South Africa, Digital Interview - Magazine)

\section{Silencing Stigma}

The stigma around COVID-19 was strongly noted in the articulations of some individuals, resulting in feelings of shame and humiliation.

"I can still feel that people are treating me as if I am a monster, even though I have fully recovered... Netizens, who had learnt about my conditions, would share my family photos on social media. They highlighted my face and exposed the rest of my family to public scrutiny... I felt bad for my family. Some netizens even blamed me for bringing the virus back but in fact I am also one of the victims" (Adam* man, 32 years, Malaysia, Facebook)

"I think the stigma is there because people don't understand the virus, neither do I, and I think the more we talk about it, the less the stigma holds power over it... Its heavy on your spirit and its heavy on your body, its heavy psychologically so you need all the support you can have from your family, the loved ones that are around you." (Busi*, aged unspecified, South Africa, digital news)

"It was traumatising because there were people sending messages broadcasting messages on WhatsApp naming and shaming me. It was horrendous to say the least, it caused so much damage, not only to my company I work for, but for my self-image-I am broken because I can't imagine that community you belong to can treat you like that" (Karen*, 27 years, South Africa, Digital News)

“...this doesn't discriminate, it touches everyone as you have seen around the world, from Prince Albert to Prince Charles to me here... it doesn't discriminate... try to be human, try to show kindness and compassion" (Busi*, unspecified, South Africa, Digital News)

\section{Discussion}

The popularity of digital media as a medium for sharing and examining health and wellness assisted in serving as a rich repository of data related to COVID-19 for this study. By harvesting and utilizing selfreported data on COVID-19 over a one-month period, we were able to extract and construct a picture of the symptomatology as well as lived experiences of individuals diagnosed with COVID-19 through the disease course. We attempted a "retrospective digital media cohort study" to document symptom trends 
and timelines of this disease. The symptom trend and timelines reported in this analysis appear to give more credence to respiratory symptoms, since shortness of breath or acute respiratory distress was the most prevalent general initial symptom and for the first five days of disease presentation. Clearly, this might not be the very initial symptom noticed by this digital media cohort, but because it is the most disabling and life threatening, the cases tended to report this more often in the first five days of this disease. The subtle initial symptoms mainly reported included a sore throat, dry cough, mild running/blocked nose, headaches and fevers. These initial non-life-threatening symptoms are often ignored until the respiratory distress appears, especially in regions where the flu is rampant, giving a plausible alternative diagnosis, and in the early periods of the disease where RT-PCR test was not readily available. Zhou et al (14) reported an expansive cohort study of patients with COVID-19 and among their symptom-watch were cough, myalgia, sputum production, diarrhoea, nausea, vomiting and fatigue. The merit (if any) of a self-report over clinical report is that it allows individuals to actively recall the trend in symptom onset. This may be useful for screening and differentiating COVID-19 from other febrile illnesses in the absence of a laboratory test. However, it is also a significant observation that the symptom trend is inclusive of other body systems like the nervous system as seen in symptoms like loss of taste and smell, dizziness, memory loss and hallucinations. The cardiovascular system is equally affected with symptom reports like chest tightness, chest aches and chest heaviness. The gastrointestinal and musculoskeletal systems are also affected with symptoms of diarrhoea and body aches reported in some of the cases. This extrapulmonary manifestations of COVID-19 has been consistently documented by other researchers $(15,4,14)$. Again, the reports on the variability of severity of symptoms with time has been documented by Zhou et al (14), who concluded that it is a function of presence of multiple organ failure, an elevated d-dimer test and older age. The responsiveness of the immune system and presence of co-morbidities are said to also predict the variability in symptom severity $(16$.

We are inexperienced to the acute and long-term consequences of COVID-19. Hence, the chronicles of individuals who elected to share their journeys are crucial in beginning to understand the response required to mitigate the undesirable sequelae. What we themed the $3 \mathrm{~F}$ response (Fright, Fight, Flight) exposed the vulnerability felt by individuals. Juxtaposed in their accounts were feelings of despair, disbelief, denial as well as acceptance and action. We note that psychological distress (7) and feelings of anxiety, uncertainty, and the stress brought by the pandemic are normal in these circumstances (17) and acknowledge that preserving mental health in the era of COVID-19 pandemic remains imperative (18-21). The call most recently, for multidisciplinary research priorities, in a position paper by an interdisciplinary group of 24 world-leading experts in mental health science, has provided an initial significant step towards addressing these issues illustrated in the cases in this study.

Pervasive in the self-reports was a sense of responsibility with concerted intentions towards safeguarding the vulnerable in the community. The need to protect by self-isolation, testing, transparency on the outcomes, contact tracing and supporting others were evident in the narratives. Pandemic fear (22), moral distress, and pandemic emotions (23) nuanced in their accounts appeared to be tempered by the sense of morality and personal agency. 
Currently, the vulnerability of humanity is openly displayed, but hope still lingers. In Africa, there is the concept of "Ubuntu", meaning "humanity" and often translated as "I am because we are," or "humanity towards others. As a philosophy, ethic and worldview, it is sometimes translated to express the universal bond of sharing that connects all humanity (24). This humanism was strongly evident in the accounts presented. The power of the collective, in the face of this relatively unknown disease and unpredictable risks, assisted in provided a sense of comfort and solidarity.

Fear, prejudices and negative attitudes appear to resound in COVID-19 discourse including the rhetoric of the COVID-19 generation (25) that adds another dimension to this argument. The self-reports illustrated accounts of discrimination and stigma as a result of a positive COVID-19 diagnosis. Understanding that stigma is not exclusive to this disease only, we propose that active social media campaigns, such as a positive twitter ash-tag campaign, may re-orientate and possibly sensitise the 'netizen' against stigmatisation following a COVID-19 diagnosis. Implementation of the WHO protocols (26) on mental health and psychosocial consideration for the outbreak in countries of the world may also help reduce victimization after a COVID-19 diagnosis. This may go a step further in encouraging people to get tested thereby reducing the spread of the disease.

\section{Conclusions}

The ubiquitous influence of social media is changing the milieu of health-related practice. For us it provided a medium, in an era of lockdown and social isolation, to explore self-reported experiences of persons with a positive COVID-19 diagnosis. We are aware of the priorities directed at critical medical care and more recently the call for high quality data on the mental health effects of the COVID-19 pandemic. With this is also the call for the broadest possible range of knowledge and insights (27). By an exposition of the lived experiences of individuals, we have begun to understand the community perspective of the influence of COVID-19 on the lives of those who are diagnosed with the disease. We are however cognisant of the limitation of judgemental sampling as opportunistic and consequently less optimal as it fails to capture perspectives from those who in this case have not used digital media to report their experiences. Notwithstanding this, as part of the community response, suggested by Marston and colleagues (27), we foresee the next step as one that would move beyond simply gathering views and instead build dialogue and reflection to co-create appropriate responses to the biopsychosocial sequelae of the disease.

\section{List Of Abbreviations}

COVID-19 Coronavirus Disease 2019

SARS-CoV-2 Severe Acute Respiratory Syndrome Coronavirus 2

WHO World Health Organization

MERS Middle Eastern Respiratory Syndrome

Page 10/16 


\section{Declarations}

\section{Ethics approval and Consent to Participate}

The study received Ethical Exemption from a Biomedical Research Ethics Committee (BREC) (reference number 00005722). This committee is registered with the South African National Health Research Ethics Council (REC-290408-009). BREC has US Office for Human Research Protections Federal-wide Assurance (FWA 678). The data accessed were available from open domain sources and hence informed consent was not solicited for this study. Principles related to confidentiality by use of pseudonyms were however ensured.

\section{Consent for Publication}

$\mathrm{N} / \mathrm{A}$

\section{Availability of data and materials}

The datasets used and analysed during the current study are available from the corresponding author on reasonable request.

\section{Competing Interests}

The authors declare no competing interests.

\section{Funding}

$\mathrm{N} / \mathrm{A}$

\section{Author's Contributions}

MOO and PG designed the study and were the primary investigators. Both authors drafted the initial manuscript, critically reviewed the manuscript for intellectual content, and subsequently revised the manuscript for publication. MOO and PG read and approved the final version of the manuscript.

\section{Acknowledgements}

The authors would like to acknowledge Ms NN Khanyile, Research Intern, who assisted in the transcription and collation of the data sets used in this study.

\section{References}

1. Huang C, Wang Y, Li X, Ren L, Zhao J, Hu Y, Zhang L, Fan G, Xu J, Gu X, Cheng Z, Yu T, Xia J, Wei Y, Wu W, Xie X, Yin W, Li H, Liu M, Xiao Y, Gao H, Guo L, Xie J, Wang G, Jiang R, Gao Z, Jin Q, Wang J, Cao B. Clinical features of patients infected with 2019 novel coronavirus in Wuhan, China. Lancet. 2020 Feb 15;395(10223):497-506. [PubMed: 31986264] 
2. Chen, N. et al. Epidemiological and clinical characteristics of 99 cases of 2019 novel coronavirus pneumonia in Wuhan, China: a descriptive study. Lancet 395, 507-513 (2020).

3. Pan L, et al., Clinical characteristics of COVID-19 patients with digestive symptoms in Hubei, China: a descriptive, cross-sectional, multicenter study, Am J Gastroenterol. 2020 https://journals.Iww.com/ajg/Documents/COVID_Digestive_Symptoms_AJG_Preproof.pdf

4. Menni C, Sudre C,H, Steves C.J, Ourselin S, Spector T,D Quantifying additional COVID-19 symptoms will save lives; The Lancet June 4, 2020 https://doi.org/10.1016/ S0140-6736(20)31281-2

5. Tan BY, Chew NW, Lee GK, et al. Psychological Impact of the COVID-19 Pandemic on Health Care Workers in Singapore. Ann Intern Med. 2020; [Epub ahead of print 6 April 2020]. doi: https://doi.org/10.7326/M20-1083

6. Li Z, Ge J, Yang M, et al. Vicarious traumatization in the general public, members, and non-members of medical teams aiding in COVID-19 control. Brain Behav Immun. 2020. [PMID: 32169498] doi:10.1016/j.bbi.2020.03.007

7. Qiu J, Shen B, Zhao M, Wang Z, Xie B, Xu Y. A nationwide survey of psychological distress among Chinese people in the COVID-19 epidemic: implications and policy recommendations. General psychiatry. 2020;33(2).

8. Neale S. Xi Jinping warns of 'demon' coronavirus as China scrambles to contain outbreak. Washington Examiner. 2020 https://www.washingtonexaminer.com/news/xi-jinping-warns-ofdemon-coronavirus-as-china-scrambles-to-contain-outbreak

9. Holmes EA, O'Connor RC, Perry VH, Tracey I, Wessely S, Arseneault L, Ballard C, Christensen H, Silver RC, Everall I, Ford T. Multidisciplinary research priorities for the COVID-19 pandemic: a call for action for mental health science. The Lancet Psychiatry. 2020 Apr 15.

10. Townsend E, Nielsen E, Allister R, Cassidy SA. Key ethical questions for research during the COVID-19 pandemic. The Lancet Psychiatry. 2020 May 1;7(5):381-3.

11. Booth A, Hannes K, Harden A, Noyes J, Harris J, Tong A. COREQ (consolidated criteria for reporting qualitative studies). Guidelines for reporting health research: a user's manual. 2014 Jul 25:214-6.

12. Patton MQ. Qualitative research \& evaluation methods: Integrating theory and practice. Sage publications; 2014 Oct 29.

13. Braun V, Clarke V, Hayfield N, Terry G. Thematic analysis. Handbook of research methods in health social sciences. 2019 Jan:843-60

14. Zhou F, Yu T, Du R, et al. Clinical course and risk factors for mortality of adult inpatients with COVID19 in Wuhan, China: a retrospective cohort study. Lancet 2020. published online March 9. https://doi.org/10.1016/S0140-6736(20)30566-3.

15. Guan WJ, Ni ZY, Hu Y, Liang WH, Ou CQ, He JX, et al. Clinical Characteristics of Coronavirus Disease 2019 in China. New Engl J Med. 2020. Early online: 29 February, 2020.

16. Del Rio C, Malani PN. 2019 Novel Coronavirus-Important Information for Clinicians. JAMA. 2020;323(11):1039-1040. 
17. Gordon J.A Coping With Coronavirus: Managing Stress, Fear, and Anxiety (2020)https://www.nimh.nih.gov/about/director/messages/2020/coping-with-coronavirusmanaging-stress-fear-and-anxiety.shtml

18. Rajkumar RP. COVID-19 and mental health: A review of the existing literature. Asian Journal of Psychiatry. 2020 Apr 10:102066.

19. Holmes EA, O'Connor RC, Perry VH, Tracey I, Wessely S, Arseneault L, Ballard C, Christensen H, Silver RC, Everall I, Ford T. Multidisciplinary research priorities for the COVID-19 pandemic: a call for action for mental health science. The Lancet Psychiatry. 2020 Apr 15.

20. Townsend E, Nielsen E, Allister R, Cassidy SA. Key ethical questions for research during the COVID-19 pandemic. The Lancet Psychiatry. 2020 May 1;7(5):381-3.

21. Pfefferbaum B, North CS. Mental health and the Covid-19 pandemic. New England Journal of Medicine. 2020 Apr 13.

22. Ornell F, Schuch JB, Sordi AO, Kessler FH. "Pandemic fear" and COVID-19: mental health burden and strategies. Brazilian Journal of Psychiatry. 2020(AHEAD).

23. Usher K, Bhullar N, Jackson D: Life in the pandemic: Social isolation and mental health. J Clin Nurs 2020 [Epub ahead of print];DOI: 10.1111/jocn.15290.

24. Gade CB. The historical development of the written discourses on ubuntu. South African Journal of Philosophy. 2011 Jan 1;30(3):303-29.

25. Rudolph C.W, Zacher H, The COVID-19 Generation": A Cautionary Note Work, Aging and Retirement, 2020, Vol. XX, No. XX, pp. 1-7 doi:10.1093/workar/waaa009

26. World Health Organisation Mental Health and Psychosocial consideration during the COVID-19 Outbreak, WHO/2019-nCoV/Mental Health/2020.1 Marston C, Renedo A, and Miles S, Community participation is crucial in a pandemic The Lancet comment 2020

DOI:https://doi.org/10.1016/S0140-6736(20)31054-0

\section{Figures}




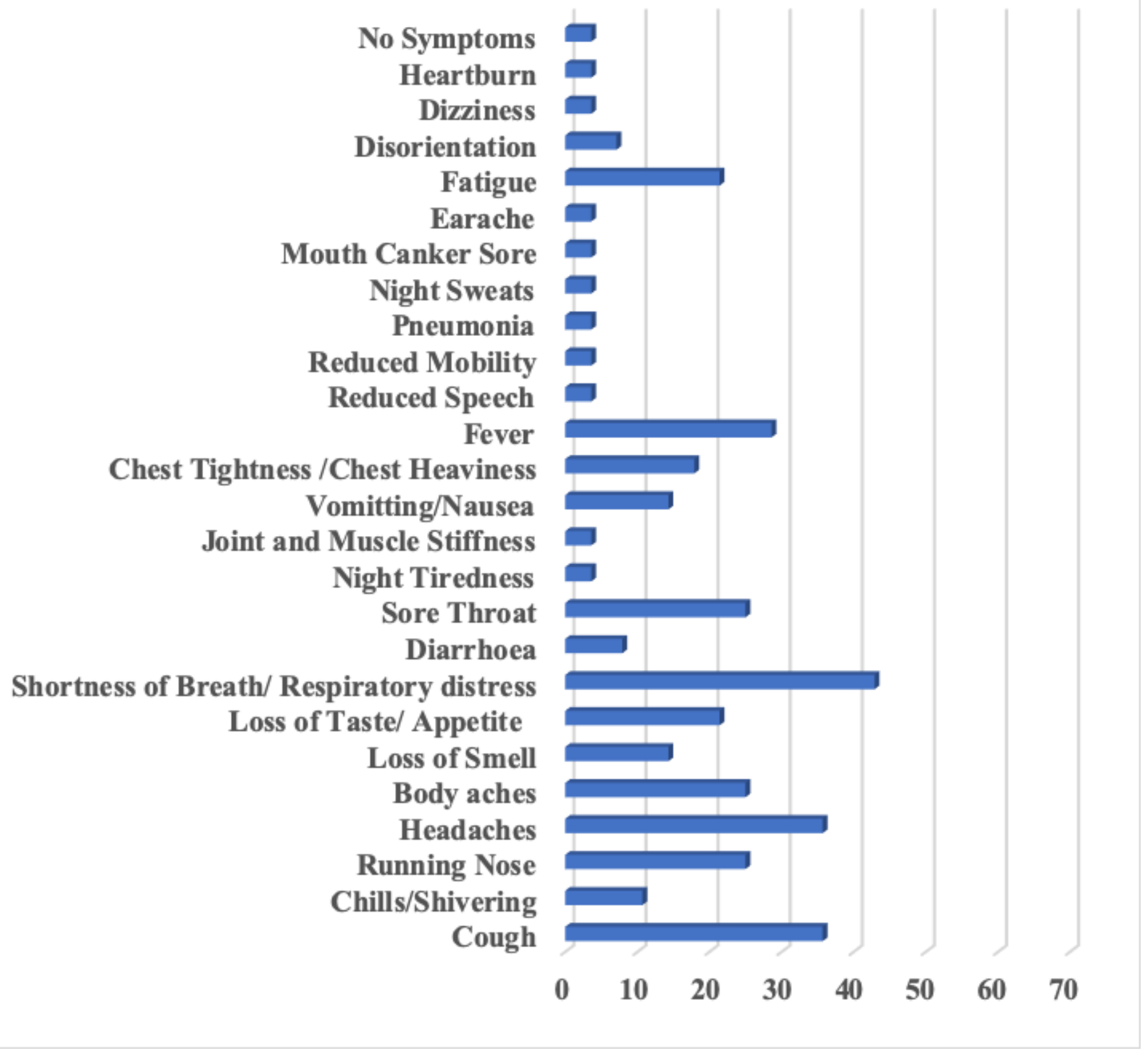

Figure 1

General Initial Symptoms 


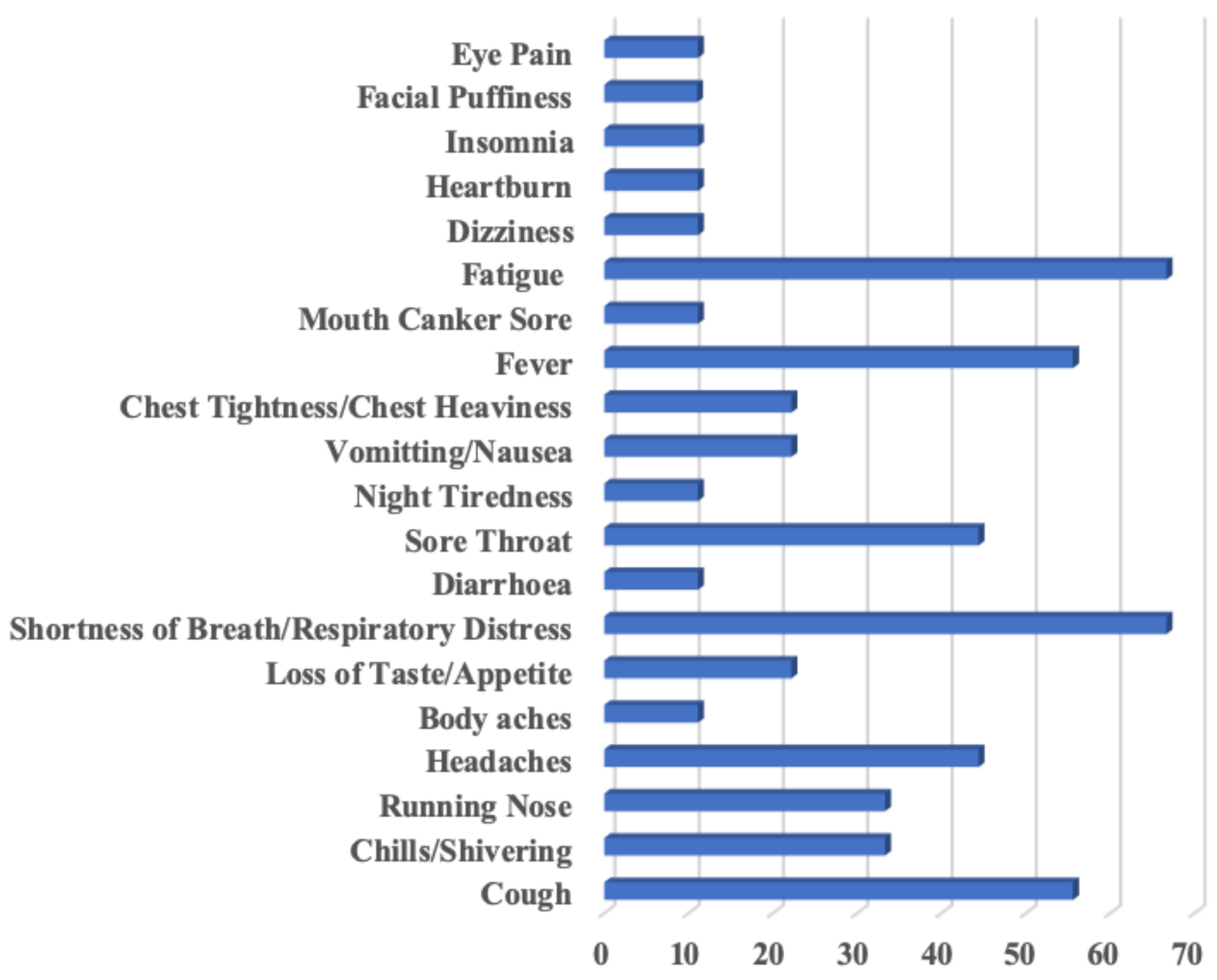

Figure 2

Symptom prevalence within the first five days of initial presentation 


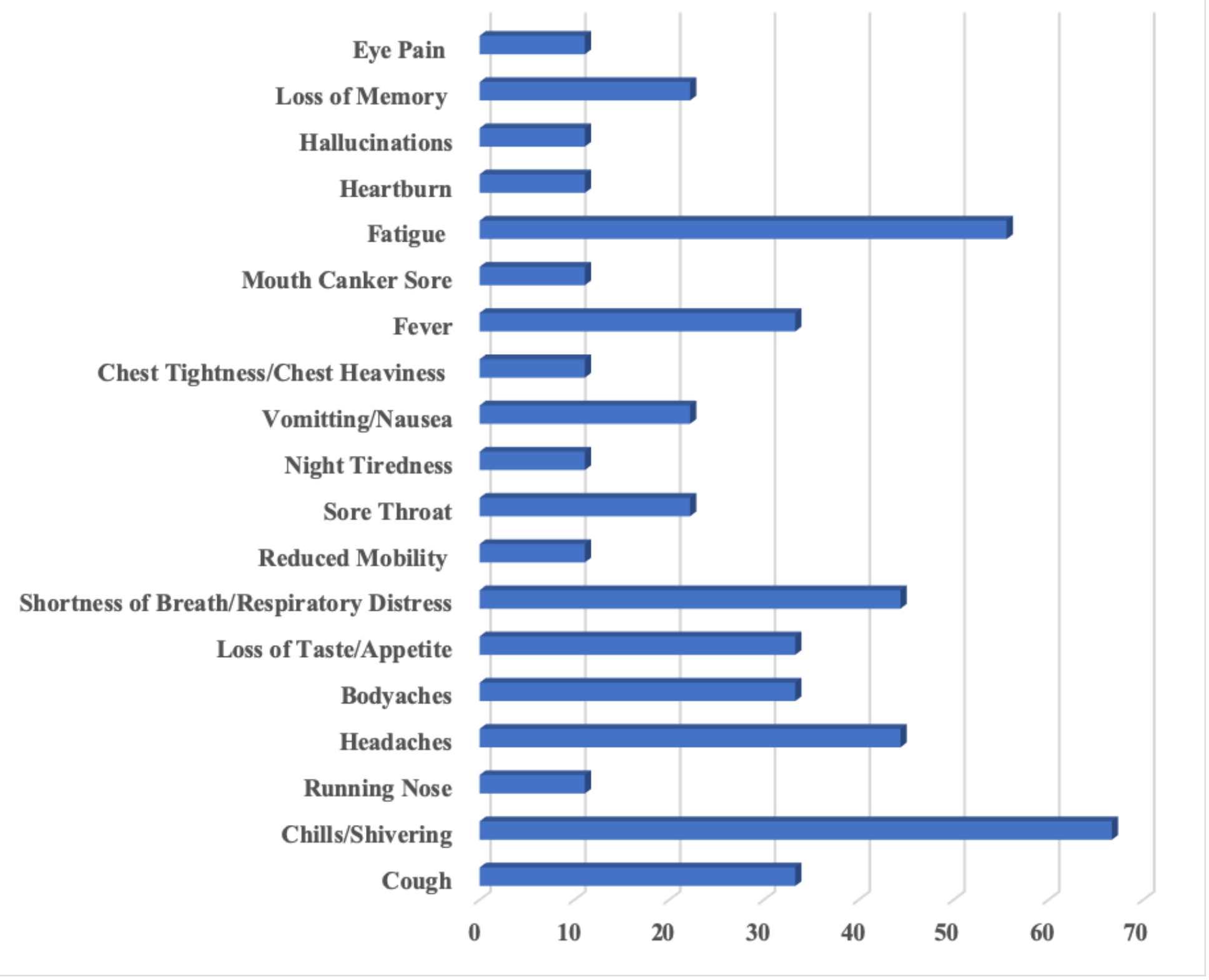

\section{Figure 3}

Symptom prevalence 6 days to 22 days 